\title{
Menstrual Pattern among University Students
}

\author{
Nabila S Mohamed ${ }^{1.2}$, Azza Mohamed Elsayed ${ }^{3}$ \\ Obstetrics \&Gynecological Nursing D. Zagazig University Egypt $1 *$ Nursing D. Collage of Applied Medical Science Hafer \\ elbaten University,KSA1.2 Obstetric and Gynecological Dept., Faculty of Nursing, Sohag University, Egypt3
}

\begin{abstract}
:
Background: Menstruation is a normal physiological phenomenon for females indicating her capability for procreation. However this normal often associated with some degree of sufferings and embarrassment.

Aim: To find out menstrual pattern and types of menstrual disorders encountered among university students. Materials and Methods: Present cross sectional study was carried out at faculty of applied medical science in haferelbatenuniversity. Total 210 girls were interviewed Information was obtained in a self-administeredpreformat in a local language related to age of menarche, total days of menstrual bleeding, regularity of cycle, and menstrual problems after verbal consent.

Results: The mean age of menarche was found to be about 19-20years, $88.6 \%$ of them were single and $54.3 \%$ were in normal BMI. A statistically significant difference observed between the study subject ages and age of menarche period interval and BMI.87.6\% of study subject complain of dysmenorrhea with $44.3 \%$ were in moderate degree and dysmenorrheal pain varies from tiredness, anxiety and vomiting. $44.8 \%$ of the study subject used mixed method to relive dysmenorrheal pain varies from hot fluid, sedative and bed rest.

Conclusions:university student complain of moderate degree of dysmenorrhea and used mixed method to relive dysmenorrheal pain.
\end{abstract}

Keywords: Menstrual pattern, university students

\section{Introduction}

Menstrual cycle is a normal physiological phenomenon for females indicating her capability for procreation. However this normal phenomenon is not an easy one. It is often associated with some degree of sufferings and embarrassment. It is common observation that every woman does experience one or other type of menstrual problems in her lifetime. The prevalence of menstrual disorders has been recorded as high as $87 \%$ [1]. The World Health Organization reports that 18 million women aged 30-55 years perceive their menstrual bleeding to be excessive[10].

Menstrual disorders frequently affect the quality of life of adolescents and young adult women, especially those who suffer dysmenorrhea and heavy menstruation [2].Dysmenorrhea is the most commongynecologic condition of adolescence occur in $60 \%$ to $93 \%$ ofadolescents. However, many do notseek medical care. Menstrual abnormalities are morecommon among younger girls, becoming less frequentas they grow older, 3-5 years after menarche.[3]

The following definitions were used to describe menstrual cycle disorders: polymenorrhea was defined as a menstruation interval lasting less than 21 days; oligomenorrhea as a menstruation interval of more than 35 days [3,4] dysmenorrhea as abdominal pain severe enough to interfere with normal activities, or require medication. Abdominal pain was ranked on four levels (the last of which was termed as dysmenorrhea), as follows: no or mild/moderate abdominal pain; severe abdominal pain

without any use of drugs, or sufficient to limit the girl's activities; severe abdominal pain treated with drugs, and/or activity limitations during bleeding days; or severe abdominal pain treated with drugs and/or activity limitations before bleeding days. Such disorders also have economic consequences in terms of health care costs due to the consumption of expensive hormonal drugs and laboratory tests[5,6].

Adolescence is the time of life between puberty and psychophysical maturity when crucial endocrinological, metabolic, somatic and psychological changes occur in girls. During this process, sequential phases mark the maturation of the complex endocrinological system that comprises the hypothalamus, pituitary gland, and ovary, and their interactions. Healthy reproductive function isthe expected endpoint of this process. [7,8].

\section{Subjects And Methods}

\section{A-Research design and setting:}

The study used a descriptive cross-sectional survey using self-report questionnaire. The study was carried out in College ofApplied Medical Science, HaferEl-Batin University at HaferEl-Batin Governorate KSA in the period from March 2015 to the end of May2015.

\section{B- Subjects}

Convenient sample of 210 students were selectedsystematically from first, second and third year toparticipate in the above mentioned settings. From medical laboratory and nursing students.

\section{C-Tools of the study:-}

Two tools were developed by the researcher to collect the data for this study.

Tool I:- An interview questionnaire was developed by theresearcher based on current literature, it wasconstructed in Arabic language based on recent andrelated literature. This tool covered the followingitems:- 
Part 1. Socio-Demographic characteristics for thestudents such as: age, marital status, number of children, BMI ect.

Part 2. Menstrual characteristics such as: age ofmenarche, period interval, duration ofmenstruation, forms and amount of blood loss

(number of pad).

Part 3. Characteristics of dysmenorrheal pain asonset of dysmenorrheal pain,occurrence of pain, siteof pain and associated symptoms, menstrual disorders.

Part 4. Effect of dysmenorrheal pain on daily activity and study of the studentsand coping methods used for relievingpain.

Tool (2). Visual analogue scale (VAS):

It is used to establish baseline level of pain. Itconsists of $10 \mathrm{~cm}$ horizontal line with words No painon the left and unbearable on the right whichrepresented a continuum of pain intensity. Painintensity was evaluated by asking the study subjectsto point on the line the number that represented theintensity of their pain. The scores of visual analoguescale was as follows: - No pain (0), Mild pain (1 - 3),Moderate pain (4 -5), Severe pain (6-8), unbearable(9-10).

\section{D-Ethical consideration}

The agreement on participation of the studysubjects was taken after the aim of the studyexplained to them. They were given an opportunity torefuse participating and they could withdraw at anystage of the research. Additionally, they were assuredthat the information would be confidential and usedfor the research purpose only.

\section{E-Methods of data collection:}

1. Approval for data collection was obtained fromthe director of Faculty of Applied MedicalScience at Hafer Al-Batin university of Hafer Al-Baten forconducting the study.

2. The tools were developed by the researcherbased on reviewing literature.

3. A pilot study was conducted on four students fortwo times separated by two weeks to ensure thereliability of the tool and to assess the student'sacceptance to be involved in the study.

4. All study subjects received the structuredinterview questionnaire to estimate thestudent's socio-demographic, menstrualcharacteristics, menstrual disorders.

\section{G-Statistical analysis}

All data were collected, coded, tabulated andsubjected to statistical analysis. Statistical analysis isperformed by statistical Package SPSS in general(version 13), also Microsoft office Excel is used fordata handling and graphical presentation.Quantitative variables are described by the Mean,Standard Deviation (SD), while qualitativecategorical variables are described by proportions andpercentages. Descriptive statistics are used to analyzethe response to individual items and the respondents

characteristics. Chi-square and P-value test used totest correlation.

\section{Results}

Table 1):- Socio-demographic data of the study sample $(\mathrm{n}=210)$

\begin{tabular}{|c|c|c|c|}
\hline \multicolumn{2}{|c|}{ Characteristics } & No & $\%$ \\
\hline \multicolumn{4}{|c|}{ Age (years) } \\
\hline- & $16-18$ & 43 & 20.5 \\
\hline - & $19-20$ & 134 & 63.8 \\
\hline - & $21-25$ & 33 & 15.7 \\
\hline \multicolumn{2}{|l|}{ Range } & \multicolumn{2}{|c|}{$16-36$} \\
\hline \multicolumn{2}{|c|}{ Mean \pm SD } & \multicolumn{2}{|c|}{$19.5 \pm 2.1$} \\
\hline \multicolumn{4}{|c|}{ Marital status } \\
\hline- & Married & 17 & 8.1 \\
\hline 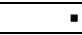 & Single & 186 & 88.6 \\
\hline - & Divorced & 7 & 3.3 \\
\hline \multicolumn{4}{|c|}{ Number of children } \\
\hline$\cdot$ & 0 & 8 & 33.3 \\
\hline - & 1 & 4 & 16.7 \\
\hline - & 2 & 8 & 33.3 \\
\hline- & 3 & 4 & 16.7 \\
\hline \multicolumn{4}{|l|}{ BMI } \\
\hline - & Underweight & 8 & 3.8 \\
\hline - & Normal & 114 & 54.3 \\
\hline - & Overweight & 69 & 32.9 \\
\hline- & Obese & 19 & 9.0 \\
\hline \multicolumn{4}{|c|}{ Medical history } \\
\hline - & No & 185 & $88.1 \%$ \\
\hline- & HTN & 5 & $2.4 \%$ \\
\hline - & Cardiac & 3 & $1.4 \%$ \\
\hline- & Renal & 4 & $1.9 \%$ \\
\hline - & DM & 2 & $1.0 \%$ \\
\hline - & Others & 11 & $5.2 \%$ \\
\hline
\end{tabular}


Table 1 shows the background characteristics of the sample. The mean age was 19.5 years with mean \pm SD $19.5 \pm$ 2.1. Majority of them were single (88.6\%). And $66.7 \%$ of married subject and have 1-3child. Regarding BMI more than half of them $54.3 \%$ were normal weight and $42 \%$ varies from overweight and obese. Finally $88.1 \%$ of study subject had no medical history.

Table 2) Relation between ages and menstrual characteristic of study subject.

\begin{tabular}{|c|c|c|c|c|c|c|c|c|c|c|}
\hline \multirow{3}{*}{\multicolumn{2}{|c|}{ Menstruation characteristics }} & \multicolumn{8}{|c|}{ Age (years) } & \multirow{3}{*}{$M C P$} \\
\hline & & \multicolumn{2}{|c|}{$16-18$} & \multicolumn{2}{|c|}{ 19-21 } & \multicolumn{2}{|c|}{$21+$} & \multicolumn{2}{|c|}{ Total } & \\
\hline & & No & $\%$ & No & $\%$ & No & $\%$ & No & $\%$ & \\
\hline \multicolumn{10}{|c|}{ Age at menarche } & \multirow[t]{5}{*}{$0.029^{*}$} \\
\hline - & $9-11$ & 5 & 11.6 & 8 & 6.0 & 7 & 21.2 & 20 & 9.5 & \\
\hline. & $11-13$ & 19 & 44.2 & 67 & 50.0 & 18 & 54.5 & 104 & 49.5 & \\
\hline - & $13-15$ & 15 & 34.9 & 51 & 38.1 & 4 & 12.1 & 70 & 33.3 & \\
\hline - & $15-17$ & 4 & 9.3 & 8 & 6.0 & 4 & 12.1 & 16 & 7.6 & \\
\hline \multicolumn{2}{|c|}{ Regularity of menstruation } & & & & & & & & & \multirow[t]{3}{*}{$0.050 *$} \\
\hline - & Yes & 24 & 55.8 & 99 & 73.9 & 20 & 60.6 & 143 & 68.1 & \\
\hline - & No & 19 & 44.2 & 35 & 26.1 & 13 & 39.4 & 67 & 31.9 & \\
\hline \multicolumn{10}{|c|}{ Inter period interval } & \multirow[t]{6}{*}{$0.007 *$} \\
\hline - & $<25$ days & 12 & 27.9 & 35 & 26.1 & 9 & 27.3 & 56 & 26.7 & \\
\hline - & 25 days & 9 & 20.9 & 51 & 38.1 & 10 & 30.3 & 70 & 33.3 & \\
\hline - & 28 days & 11 & 25.6 & 32 & 23.9 & 10 & 30.3 & 53 & 25.2 & \\
\hline - & $>28$ days & 3 & 7.0 & 14 & 10.4 & 2 & 6.1 & 19 & 9.0 & \\
\hline- & No pattern & 8 & 18.6 & 2 & 1.5 & 2 & 6.1 & 12 & 5.7 & \\
\hline \multicolumn{10}{|c|}{ Duration of period } & \multirow[t]{5}{*}{0.577} \\
\hline - & $2-3$ & 4 & 9.3 & 6 & 4.5 & 1 & 3.0 & 11 & 5.2 & \\
\hline . & $4-5$ & 11 & 25.6 & 50 & 37.3 & 14 & 42.4 & 75 & 35.7 & \\
\hline - & $6-7$ & 25 & 58.1 & 73 & 54.5 & 16 & 48.5 & 114 & 54.3 & \\
\hline - & +More & 3 & 7.0 & 5 & 3.7 & 2 & 6.1 & 10 & 4.8 & \\
\hline \multicolumn{10}{|c|}{ Type of blood } & \multirow[t]{4}{*}{0.186} \\
\hline - & Fresh & 8 & 18.6 & 37 & 27.6 & 4 & 12.1 & 49 & 23.3 & \\
\hline - & Clotted & 4 & 9.3 & 18 & 13.4 & 7 & 21.2 & 29 & 13.8 & \\
\hline - & Mixed & 31 & 72.1 & 79 & 59.0 & 22 & 66.7 & 132 & 62.9 & \\
\hline \multicolumn{10}{|c|}{ Number of napkin } & \multirow[t]{4}{*}{0.691} \\
\hline - & Slight (once daily) & 4 & 9.3 & 15 & 11.2 & 6 & 18.2 & 25 & 11.9 & \\
\hline - & Intermediate (2-3 daily) & 28 & 65.1 & 83 & 61.9 & 21 & 63.6 & 132 & 62.9 & \\
\hline - & Heavy (4+ daily) & 11 & 25.6 & 36 & 26.9 & 6 & 18.2 & 53 & 25.2 & \\
\hline
\end{tabular}

MCP: Mont Carlo exact probability* $\mathrm{P}<0.05$ (significant)

Regarding relation between age and menstrual characteristic table 2 shows statistically significant observed between age group 19-21 years and menstrual characteristic as $49.5 \%$ of the study subject started their menses at 11-13 years and $73.9 \%$ of this group have regular menses also $64 \%$ of this age group have 25 -28day period interval.

Table 3) Relation between BMI of the study subject and menstrual pattern

\begin{tabular}{|c|c|c|c|c|c|c|c|c|c|c|}
\hline \multirow{3}{*}{\multicolumn{2}{|c|}{ Menstruation data }} & \multicolumn{8}{|c|}{ BMI } & \multirow[t]{3}{*}{$M C P$} \\
\hline & & \multicolumn{2}{|c|}{ Underweight } & \multicolumn{2}{|c|}{ Normal } & \multicolumn{2}{|c|}{ Overweight } & \multicolumn{2}{|c|}{ Obese } & \\
\hline & & No & $\%$ & No & $\%$ & No & $\%$ & No & $\%$ & \\
\hline \multicolumn{10}{|c|}{ Age at menarche } & \multirow[t]{5}{*}{$0.033 *$} \\
\hline - & $9-11$ & 0 & 0.0 & 12 & 10.5 & 8 & 11.6 & 0 & 0.0 & \\
\hline - & $11-13$ & 1 & 12.5 & 50 & 43.9 & 41 & 59.4 & 12 & 63.2 & \\
\hline . & $13-15$ & 6 & 75.0 & 43 & 37.7 & 17 & 24.6 & 4 & 21.1 & \\
\hline - & $15-17$ & 1 & 12.5 & 9 & 7.9 & 3 & 4.3 & 3 & 15.8 & \\
\hline \multicolumn{10}{|c|}{ Regularity of menstruation } & \multirow[t]{3}{*}{0.135} \\
\hline - & Yes & 5 & 62.5 & 83 & 72.8 & 40 & 58.0 & 15 & 78.9 & \\
\hline$\overline{-}$ & No & 3 & 37.5 & 31 & 27.2 & 29 & 42.0 & 4 & 21.1 & \\
\hline \multicolumn{10}{|c|}{ Inter period interval } & \multirow[t]{6}{*}{0.183} \\
\hline - & $<25$ days & 1 & 12.5 & 32 & 28.1 & 19 & 27.5 & 4 & 21.1 & \\
\hline$\cdot$ & 25 days & 4 & 50.0 & 45 & 39.5 & 16 & 23.2 & 5 & 26.3 & \\
\hline - & 28 days & 1 & 12.5 & 21 & 18.4 & 23 & 33.3 & 8 & 42.1 & \\
\hline - & $>28$ days & 2 & 25.0 & 9 & 7.9 & 6 & 8.7 & 2 & 10.5 & \\
\hline - & No pattern & 0 & 0.0 & 7 & 6.1 & 5 & 7.2 & 0 & 0.0 & \\
\hline \multicolumn{10}{|c|}{ Duration of period } & \multirow[t]{5}{*}{0.616} \\
\hline - & $2-3$ & 0 & 0.0 & 4 & 3.5 & 4 & 5.8 & 3 & 15.8 & \\
\hline - & $4-5$ & 2 & 25.0 & 43 & 37.7 & 25 & 36.2 & 5 & 26.3 & \\
\hline - & $6-7$ & 5 & 62.5 & 62 & 54.4 & 37 & 53.6 & 10 & 52.6 & \\
\hline$\cdot$ & More & 1 & 12.5 & 5 & 4.4 & 3 & 4.3 & 1 & 5.3 & \\
\hline \multicolumn{10}{|c|}{ Type of blood } & \multirow[t]{4}{*}{0.407} \\
\hline - & Fresh & 3 & 37.5 & 29 & 25.4 & 14 & 20.3 & 3 & 15.8 & \\
\hline - & Clotted & 2 & 25.0 & 18 & 15.8 & 8 & 11.6 & 1 & 5.3 & \\
\hline - & Mixed & 3 & 37.5 & 67 & 58.8 & 47 & 68.1 & 15 & 78.9 & \\
\hline \multicolumn{10}{|c|}{ Number of napkin } & \multirow[t]{4}{*}{0.149} \\
\hline - & Slight (once daily) & 3 & 37.5 & 12 & 10.5 & 10 & 14.5 & 0 & 0.0 & \\
\hline - & Intermediate (2-3 daily) & 3 & 37.5 & 74 & 64.9 & 40 & 58.0 & 15 & 78.9 & \\
\hline- & Heavy (4+ daily) & 2 & 25.0 & 28 & 24.6 & 19 & 27.5 & 4 & 21.1 & \\
\hline
\end{tabular}

MCP: Mont Carlo exact probability* $\mathrm{P}<0.05$ (significant) 
Table 3 shows relation between BMI of the study subject and menstrual pattern. There were a statistically significant difference observed between BMI and age of menarche as 59.4\% and $63.2 \%$ of overweight and obese girls respectively start their menstruation at age 11-13 years compared to12.5\% and $43.9 \%$ of underweight and normal weight girls respectively.

Regarding rest menstrual characteristic there were non-statistically significant observed between them and BMI.

Table 4) Distribution of the study subject according to presence of dysmenorrhea

\begin{tabular}{|c|c|c|c|}
\hline \multicolumn{2}{|c|}{ Menstrual pain } & No & $\%$ \\
\hline \multicolumn{4}{|c|}{ Pain with period } \\
\hline - & Yes & 184 & 87.6 \\
\hline$\cdot$ & No & 26 & 12.4 \\
\hline \multicolumn{4}{|c|}{ Degree of pain } \\
\hline$\cdot$ & No & 26 & 12.4 \\
\hline$\cdot$ & Slight & 17 & 8.1 \\
\hline$\cdot$ & Intermediate & 93 & 44.3 \\
\hline$\cdot$ & Severe & 53 & 25.2 \\
\hline$\cdot$ & Intolerable & 21 & 10.0 \\
\hline \multicolumn{4}{|c|}{ Onset of pain } \\
\hline$\cdot$ & With first period & 113 & 61.4 \\
\hline$\cdot$ & After 6 months & 27 & 14.7 \\
\hline$\cdot$ & After 1 year & 25 & 13.6 \\
\hline$\cdot$ & After 2 years & 18 & 9.8 \\
\hline$\cdot$ & More & 1 & 0.5 \\
\hline \multicolumn{4}{|c|}{ Time of pain } \\
\hline ! & Immediately before period & 39 & 21.2 \\
\hline$\cdot$ & With period and lasts for 1 day & 55 & 29.9 \\
\hline$\cdot$ & With period and lasts for 2 days & 56 & 30.4 \\
\hline - & Days before period & 34 & 18.5 \\
\hline \multicolumn{4}{|c|}{ Site of pain } \\
\hline$\cdot$ & Lower abdomen & 31 & 16.8 \\
\hline$\cdot$ & Low back pain & 17 & 9.2 \\
\hline$\cdot$ & Lower limbs & 26 & 14.1 \\
\hline$\cdot$ & All sites & 110 & 59.8 \\
\hline \multicolumn{4}{|c|}{ Absence from pain } \\
\hline$\cdot$ & No & 94 & 44.8 \\
\hline$\cdot$ & One day & 76 & 36.2 \\
\hline$\cdot$ & Two days & 34 & 16.2 \\
\hline$\cdot$ & More & 6 & 2.9 \\
\hline
\end{tabular}

When investigating presence of dysmenorrhea among nursing student table 4 shows that $87.6 \%$ of the study subject reported presence of pain with menstruation. $61.3 \%$ reported that this pain started with their menarche. According to Likert scale $44.3 \%$ of study subject report intermediate degree of pain. And $44.8 \%$ of study subject reported that this pain not affect their study.

Table 5) Relation between regularity of menstruation of the study and presence of dysmenorrheal pain.

\begin{tabular}{|c|c|c|c|c|c|c|}
\hline \multirow{3}{*}{\multicolumn{2}{|c|}{ Pain data }} & \multicolumn{4}{|c|}{ Regularity of menstruation } & \multirow[t]{3}{*}{ MCP } \\
\hline & & \multicolumn{2}{|l|}{ Yes } & \multicolumn{2}{|l|}{ No } & \\
\hline & & No & $\%$ & No & $\%$ & \\
\hline \multicolumn{2}{|c|}{ Pain with period } & & & & & \multirow[t]{3}{*}{0.894} \\
\hline - & Yes & 125 & 87.4 & 59 & 88.1 & \\
\hline - & No & 18 & 12.6 & 8 & 11.9 & \\
\hline \multicolumn{2}{|c|}{ Degree of pain } & & & & & \multirow[t]{6}{*}{0.921} \\
\hline - & No & 18 & 12.6 & 8 & 11.9 & \\
\hline - & Slight & 13 & 9.1 & 4 & 6.0 & \\
\hline - & Intermediate & 61 & 42.7 & 32 & 47.8 & \\
\hline - & Severe & 37 & 25.9 & 16 & 23.9 & \\
\hline - & Intolerable & 14 & 9.8 & 7 & 10.4 & \\
\hline \multicolumn{2}{|c|}{ Onset of pain } & & & & & \multirow[t]{6}{*}{0.956} \\
\hline - & With first period & 76 & 60.8 & 37 & 62.7 & \\
\hline - & After 6 months & 19 & 15.2 & 8 & 13.6 & \\
\hline - & After 1 year & 17 & 13.6 & 8 & 13.6 & \\
\hline - & After 2 years & 12 & 9.6 & 6 & 10.2 & \\
\hline - & More & 1 & 0.8 & 0 & 0.0 & \\
\hline \multicolumn{2}{|c|}{ Time of pain } & & & & & \multirow[t]{5}{*}{0.785} \\
\hline - & Immediately before period & 24 & 19.2 & 15 & 25.4 & \\
\hline$\cdot$ & With period and lasts for 1 day & 39 & 31.2 & 16 & 27.1 & \\
\hline - & With period and lasts for 2 days & 38 & 30.4 & 18 & 30.5 & \\
\hline - & Days before period & 24 & 19.2 & 10 & 16.9 & \\
\hline \multicolumn{2}{|c|}{ Site of pain } & & & & & \multirow[t]{5}{*}{0.392} \\
\hline$\cdot$ & Lower abdomen & 25 & 20.0 & 6 & 10.2 & \\
\hline - & Low back pain & 11 & 8.8 & 6 & 10.2 & \\
\hline - & Lower limbs & 18 & 14.4 & 8 & 13.6 & \\
\hline - & All sites & 71 & 56.8 & 39 & 66.1 & \\
\hline \multicolumn{2}{|c|}{ Absence from pain } & & & & & \multirow[t]{5}{*}{0.134} \\
\hline - & No & 68 & 47.6 & 26 & 38.8 & \\
\hline - & One day & 54 & 37.8 & 22 & 32.8 & \\
\hline - & Two days & 18 & 12.6 & 16 & 23.9 & \\
\hline - & More & 3 & 2.1 & 3 & 4.5 & \\
\hline
\end{tabular}

MCP: Mont Carlo exact probability 
Figure 1) Distribution of menstrual accompanied symptoms reported by study subject

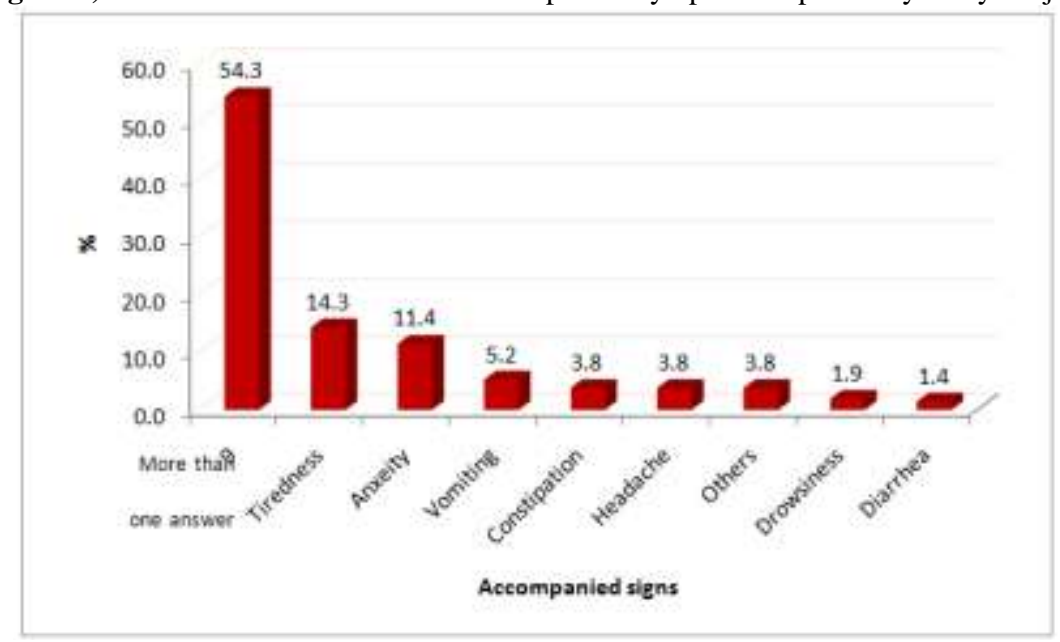

Figure 1 illustrate distribution of menstrual accompanied symptoms reported by study subject more than half $54.3 \%$ of the study subject reported presence of more than one symptoms with $14.3 \%$ and $11.4 \%$ reported tiredness and anxiety respectively.

Figure 2) Method used to relive dysmenorrheal pain reported by study subject

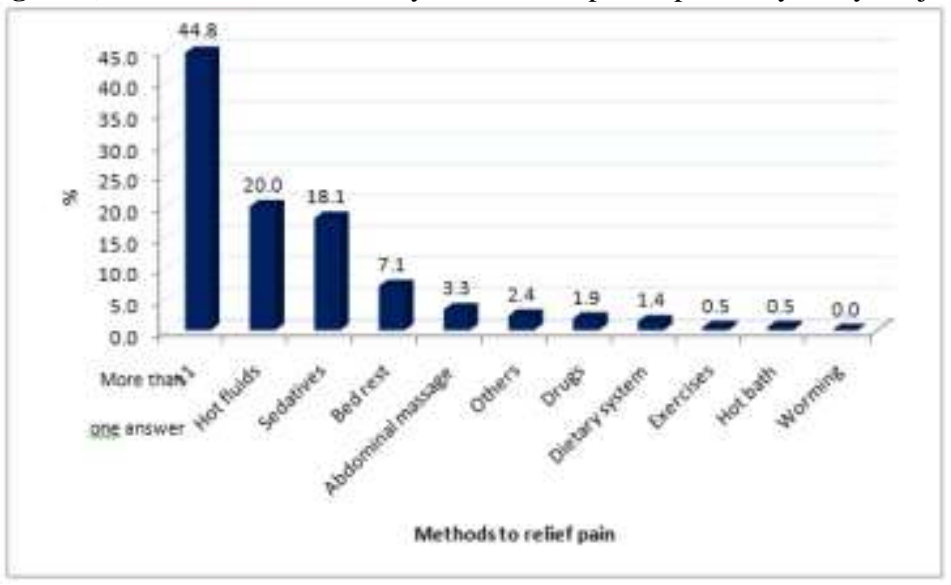

Figure 2 shows method used by the study subjects to relive dysmenorrheal pain $20 \%$ of the study subject reported hot fluids as a method used to relive pain also $18.1 \%$ used sedative but $44.8 \%$ reported more than one methods for relieving pain during menstruation

Figure 3) Prevalence of menstrual disorders

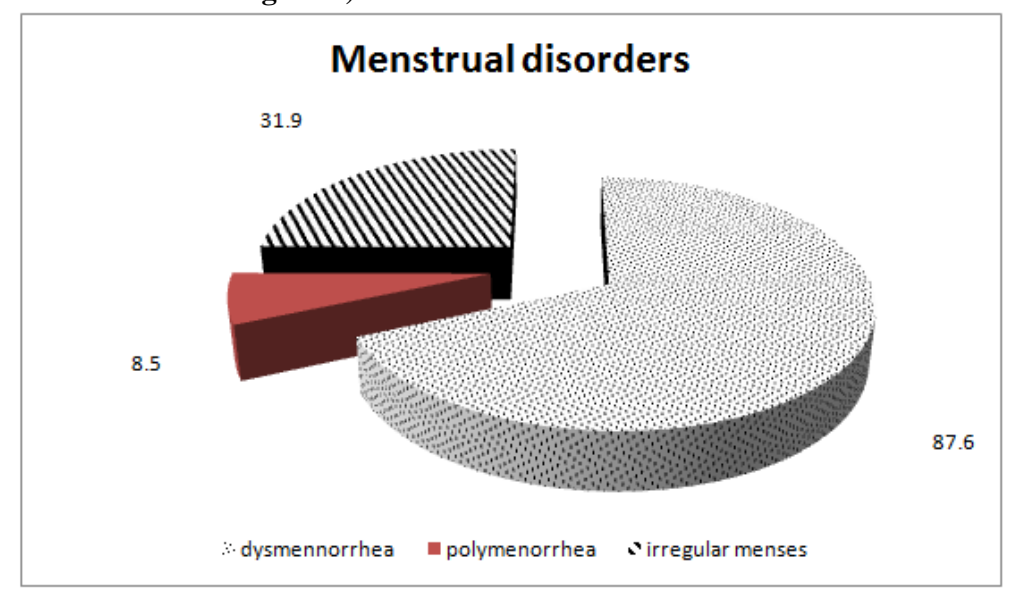

Figure 3 shows menstrual disorders among study subjects there were $87.6 \%$ of students reported presence of dysmenorrhea , $8.5 \%$ complain of polymenorrhea and $31.5 \%$ reported irregular menses. 


\section{Discussion}

This study was conducted to find out menstrual pattern and types of menstrual disorders encountered among university students. The present study results showed that more than half the study sample were in age group 19-20 years with mean \pm SD $19.5 \pm 2.1$ and majority of them were single. This is the age range of university students and mainly university students delay marriage until finishing study.

Regarding BMImore than half of the study subject have normal BMI and one third of them were overweight only 9\% of them were obese.In a similar study Amazaetal., 2012 who study characteristics of menstrual cycle among university students found that distribution of BMI among the study subjects wereunderweight BMI17.8\%, Average weight $71 \%$, Over weight $11.2 \%$.

Regarding relation between age and menstrual characteristics there were a statistically significant difference between age group 19-21 years and regularity of menstruation. As more than half of the study subject have their period interval 25-28 day were in age group 19-21 years this finding was disagreement with Amazaetal., 2012 found that 81.2\% of the study subject have their period interval within normal range in age group 26-29 year.

The present study result found that majority of thestudy subject in age group have their age of menarche at 11-15 years. which correlates with study byBegum et al. (2009). Also this finding was in agreement withVarsharani V , Chandrashekhar $\mathrm{H}(2013)$ who reported that out of 88 menarchic girls, $62.5 \%$ attained menarche atthe age of 13 years. The youngest age of menarchewas 11 years and oldest was 14 years.Among slum girls, 96 menarchic girls, most ofthe girls $57.29 \%$ attained menarche at the ageof 13 years.

Also Amazaetal., 2012 reported that age at menarche was 9 years, while the maximum age atmenarche was 17 years with an average mean of 13 years.

Jamicson and Steege 2010who found that half of girls were unable to focus on their courses (50\%), expressed an inability to answer the questions in the exams despite having the knowledge (26.9\%), missed school (18.6\%), and were unable to take tests $(4.5 \%)$. One third of the subjects $(31.8 \%)$ had problematic relationships with their families due to dysmenorrhea. This finding in disagreement with the present study result as nearly half of the study subject reported that menstruation don't affect their study and there was no absenteeism from collage during menstrual cycle. Regarding presence menstrual accompanied symptoms reported by study subject the present study results mention that anxiety and tiredness was the most accompanied symptoms in the opposite sideLee et al. (2006) a "long cycle" was a common menstrual disorder among adolescent girls.

Regarding presence of dysmenorrheal pain $86 \%$ of the study subject reported presence of pain with menstruation differentiated to $8.1 \%$ mild 44.3 moderate, $25.9 \%$ sever and 9.8 intolerable this finding was in agreement with the study conducted byAmazaetal., 2012 who found that $60.2 \%, 29.7 \%$ and 14.4\% respondentssuffered from mild, moderate and severe grades of pain. Also this finding correlated correlate with study conducted by Amita et al. 2008 that reported grades of pains as $63.29 \% 30.37 \%$ and $6.32 \%$ from mild, moderate and severe pains respectively.In the present study when investigating relation between pain and regularity of menstruation the present study found that $87.4 \%$ reported regular menses and $88.1 \%$ reported irregular menses as pain was similar in both regular and irregular menses. This finding controversy with Desalegn et al. 2009, that there were morerespondents had irregular painful menstrual cycles. Also this finding as against results of Amazaetal., 2012 dysmenorrheal was more common among those who had regularcycles.

Concerning common coping methods forrelieving dysmenorrheal pain, the current studydemonstrates that the most previous coping methodsused by the majority of the students for menstrualpain include analgesics, hot fluids and bed rest inorder. And nearly half of them mix the previous three method to cope with menstrual pain. This result was agreed with Allaire and Wells(2009)who reported that female adolescents found that theparticipants with dysmenorrhea reported usingmultiple treatments to relieve their symptoms: rest $(58 \%)$, medications $(52 \%)$, hot fluid $(26 \%)$, tea(20\%), exercise $(15 \%)$, and herbs $(7 \%)$

\section{Conclusion}

The present study has determined age at menarche, marital status and average menstrual cycle among thefemalenursing and medical laboratory students of university of hafer-elbaten. As well as degree of dysmenorrheal pain and coping methods used to relive pain.

\section{Reference}

[1]. Narayan K.A. (2010): "Puberty Rituals, Reproductive Knowledge and Health of Adolescent Schoolgirls in South India.", Asia Pacific Population Journal, Vol. 16, No. 2, 224-236.

[2]. CakirM.Okten, A(2007): Menstrual pattern and common menstrual disorders among university students in Turkey. Pediatrics International, 2007, 49:938-942.

[3]. Adams Paula J(2006). Dysmenorrhea Pediatrics in Review Vol.27 No.2 February 2006.386-387

[4]. Petrozza J, Poley K(1999): Dysfunctional uterine bleeding. In Glass's officegynecology. 5th edition. Edited by Curtis MG, Hopkins MP. Baltimore:Williams\& Wilkins:241-264.

[5]. Speroff L, Glass RH, Kase NG(2004): Dysfunctional uterine bleeding. In ClinicalGynecologic Endocrinology and Infertility. 5th edition. Baltimore: Williams \&Wilkins; 2004:575-593.

[6]. World Health Organization(1992): International Statistical Classification of Diseasesand Related Health Problems, Tenth Revision. Geneva, Switzerland: WorldHealth Organization; 1992.

[7]. World Health Organization(1977): Manual of the International StatisticalClassification of Diseases, Injuries, and Causes of Death, Ninth Revision.Geneva, Switzerland: World Health Organization; 1977.

[8]. Tanner JM: Growth at adolescence. 2nd edition. Oxford: Blackwell Scientific; 1962.359-360

[9]. Slap GB.(2003): Menstrual disorders in adolescence. Best Pract Res ClinObstetGynaecol 2003, 17(1):75-92

[10]. Cakir M et al. Okten, A(2007): Menstrual pattern and common menstrual disorders among university students in Turkey. Pediatrics International, 2007, 49:938-942.

[11]. Allaire MK., Wells SR.,(2009): Complementary and Alternative Medicine in Pregnancy a Survey of North Carolina Certified Nurse-Midwives, Obstetrics Gynecology, $2009 ; 95:$ p19-23. 
[12]. Varsharani V Kendre, Chandrashekhar H Ghattergi(2013): A study on menstruation and personal hygiene among adolescent girls of government medical collage Solapur, National Journal of Community Medicine Volume 4Issue 2Apr - June 2013. pISSN 09763325. eISSN 22296816.

[13]. Amaza DS, Sambo N, Zirahei1 JV, Dalori DM (2012): Menstrual Pattern among Female Medical Students in University of Maiduguri, Nigeria British Journal of Medicine \& Medical Research 2(3): 327-337, 2012www.sciencedomain.org.

[14]. Desalegn, T.Z., Berihun, M., Abay, M. (2009). Age at menarche and the menstrual pattern ofsecondary school adolescents in north-west Ethiopia. BMC Women's Health, 9-29.

[15]. Amita S., Dukhu k., Harminder S., Bithika N., Prabhakar S.,(2008); Prevalence and Severity of Dysmenorrhea: A problem Related to Menstruation, Among First and Second Year Female Medical Students Indian J. Physiol. Pharmacol. 2008; 52 (4) : 389-397.

[16]. Begum, J., Hossain, A.M., Nazneen, S.A. (2009). Menstrual pattern and common menstrual disorders among students in Dinajpur Medical College Dinajpur. Med. Col. J., 2(2), 37-43.

[17]. Jamicson R., and Steege E,.(2010): Legal Issue for Nurses When Patient Use Complementary and Alternative Medicine, American Journal maternity child nursing, 2010; 27(2), p 119 